KLEINE TEXTE FÜR VORLESUNGEN UND ÜBUNGEN BEGRLANDET VON HANS LIETZMANN

\title{
FRÜHNEUHOCHDEUTSCHES GLOSSAR
}

\author{
VON \\ ALFRED GÖTZE
}

5. AUFLAGE

VERLAG WALTER DE GRUYTER \& CO.

BERLIN I956 
Archiv-Nr. $333256 / 101$ 
Herrn

\section{Professor Dr. Emil Jacobs}

in Treue $z u$ eigen 
